\title{
Cardiac Transplantation: Update on a Road Less Traveled
}

\author{
Tripti Gupta, MBBS, ${ }^{1}$ Selim R. Krim, MD ${ }^{1,2,3}$ \\ ${ }^{1}$ Department of Cardiology, John Ochsner Heart and Vascular Institute, Ochsner Clinic Foundation, New Orleans, LA ${ }^{2}$ Section of \\ Cardiomyopathy and Heart Transplantation, John Ochsner Heart and Vascular Institute, Ochsner Clinic Foundation, New Orleans, LA ${ }^{3}$ The \\ University of Queensland Faculty of Medicine, Ochsner Clinical School, New Orleans, LA
}

Background: With an aging population, the prevalence of heart failure continues to rise. The use of guideline-directed medical therapy and mechanical circulatory support devices has helped to improve outcomes, but cardiac transplantation remains the definitive treatment for end-stage heart failure.

Methods: We provide an update on cardiac transplantation and review indications, contraindications, and important aspects of perioperative and postoperative management. We also highlight the current challenges faced by the transplant community.

Results: Advances in surgical techniques and immunosuppression have increased survival rates posttransplant. However, the risk of rejection and adverse effects from chronic immunosuppression continue to affect long-term outcomes.

Conclusion: Despite tremendous progress in the management of cardiac transplant patients, we have much opportunity to further optimize cardiac transplant waitlisting and improve posttransplant outcomes.

Keywords: Graft rejection, heart failure, heart transplantation, immunosuppression, primary graft dysfunction, waiting lists

Address correspondence to Selim R. Krim, MD, Section of Cardiomyopathy and Heart Transplantation, John Ochsner Heart and Vascular Institute, Ochsner Clinic Foundation, 1514 Jefferson Hwy., New Orleans, LA 70121. Tel: (504) 842-4721. Email: selim.krim@ochsner.org

\section{INTRODUCTION}

With the aging of our population and the epidemics of hypertension, coronary artery disease, and obesity, the incidence and prevalence of heart failure (HF) continue to rise. Currently available guideline-directed medical therapy has helped tremendously to improve symptoms and survival of patients with HF with reduced ejection fraction; however, a large number of patients still reach stage D HF. ${ }^{1}$ Mechanical circulatory support (MCS) has emerged as a viable strategy to bridge patients to cardiac transplantation or as an alternative for patients who are not candidates for transplantation. MCS-related complications such as stroke, pump thrombosis, and suboptimal long-term survival remain a challenge. Therefore, cardiac transplantation remains the gold standard and only cure for stage D HF. ${ }^{1}$ This article provides an update on cardiac transplantation, with discussions of indications, contraindications, and perioperative and postoperative management. We address current challenges faced by the transplant community, discuss the updated United Network for Organ Sharing (UNOS) listing system and its implications, and propose future directions.

\section{BRIEF HISTORIC OVERVIEW}

Alexis Carrel began experiments with vascular anastomoses in the 1890s, but it wasn't until 1967 that Dr. Christiaan Barnard successfully completed the first orthotopic cardiac transplantation. ${ }^{2}$ The 54-year-old recipient remained alive for 18 days postoperatively but died of Pseudomonas pneumonia. ${ }^{2}$ Inadequate understanding of the rejection pro- cess curbed further advancements in cardiac transplantation until Dr. Norman Shumway's discovery in 1978 of cyclosporine A as an immunosuppressant. This breakthrough led to a dramatic improvement in posttransplant outcomes. ${ }^{2}$ Figure 1 shows a timeline of advances in surgical techniques that made cardiac transplantation possible. ${ }^{2}$

\section{CARDIAC TRANSPLANTATION BY THE NUMBERS}

In 2016, 3,209 heart transplants were performed; 2,764 were performed in adult recipients. Between 2005 and 2016, the number of waitlisted patients increased by $57 \%$, but the overall heart transplant rates decreased by $27.8 \%$ (129.0 to 93.1 per 100 waitlist years). ${ }^{3}$ Transplant rates have not increased at the same rate as the listings, largely because of a mismatch between demand and supply. The donor rate has not increased and varies by geography. The trend to perform cardiac transplantation in patients $>65$ years of age, patients with the highest UNOS status, and patients with blood group $A B$ is growing. ${ }^{3}$ Pretransplant mortality on the waitlist decreased from 14.6 deaths per 100 waitlist years in 2015 to 9.7 deaths per 100 waitlist years in $2016 .{ }^{3}$ In a 2014 analysis of cardiac transplantation recipients, the median survival time was approximately 10.7 years, with $84.5 \% 1$ year survival and $72.5 \% 5$-year survival rates. ${ }^{4}$

\section{INDICATIONS AND CONTRAINDICATIONS FOR CARDIAC TRANSPLANT}

The primary indication for cardiac transplantation is persistent advanced chronic HF despite optimal medical 


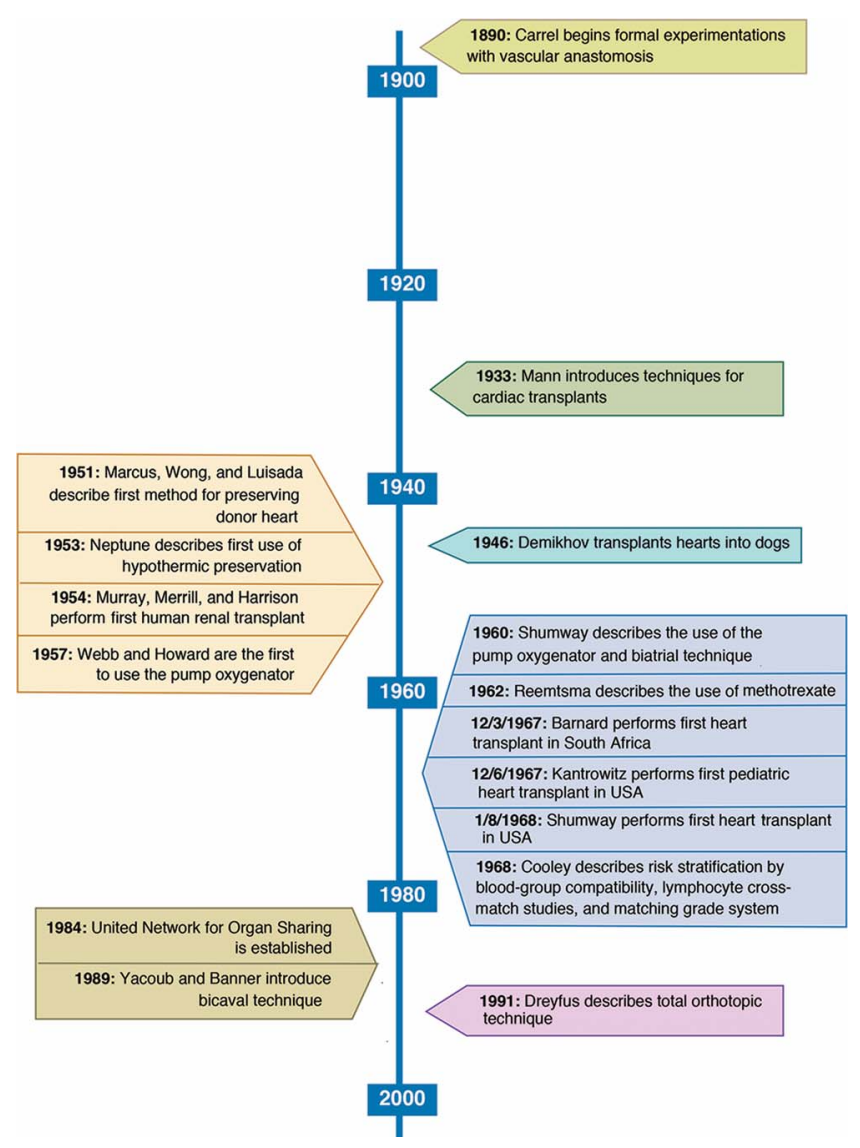

Figure 1. Advancements in cardiac transplantation. ${ }^{2}$

management. ${ }^{5}$ Table 1 lists common indications and contraindications for cardiac transplantation proposed by the American College of Cardiology and the American Heart Association. ${ }^{6-7}$ Examples of absolute contraindications are irreversible liver disease or pulmonary parenchymal disease, severe symptomatic cerebrovascular disease, and a history of solid organ or hematologic malignancy. Patients should always be referred to an advanced HF center for evaluation and risk assessment. In addition to the cardiopulmonary exercise test, the Heart Failure Survival Score and Seattle Heart Failure Model are common diagnostic tools used to assess the severity of HF and determine candidacy for cardiac transplantation. . $^{5-7}$

\section{UNITED NETWORK FOR ORGAN SHARING WAITLIST}

UNOS assigns all transplant candidates a status based on their severity of illness, geographic distance between the donor and recipient, length of time on the waitlist, and blood group compatibility. ${ }^{8}$ Prior to October 18,2018 , the highest status, $1 \mathrm{~A}$, was assigned to patients who were seriously ill and had an expected survival of $<1$ month. ${ }^{8}$ These patients were typically in the hospital, on mechanical ventilation, on high doses of inotropic drugs, or required an intraaortic balloon pump or percutaneous MCS devices to maintain cardiac output. ${ }^{8}$ Status $1 \mathrm{~B}$ was assigned to patients who were stable on lower-dose inotropic therapy or on durable MCS. Status 2 included stable ambulatory patients not on inotropic therapy. ${ }^{8}$
As of October 18, 2018, this system was replaced by a new heart allocation system summarized in Table $2 .^{8}$ Briefly, the new allocation system was designed to improve utilization of donor hearts by modifying geographical distribution to allow broader sharing of the highest status patients and to reduce waitlist mortality. ${ }^{8}$

\section{PANEL REACTIVE ANTIBODIES}

While a patient is awaiting a donor heart, calculated panel reactive antibodies (cPRA) can be measured to stratify the risk of rejection posttransplant. ${ }^{9}$ cPRA estimates the probability that a recipient will have an unacceptable donor based on the presence of incompatible antigens in the donor pool. The higher the cPRA, the higher the likelihood of incompatibility and risk of rejection posttransplant. ${ }^{9}$ Therefore, patients with high cPRA have longer wait times and poorer outcomes. Populations at risk for high cPRA are those with a history of blood transfusions, pregnancy, implant of homograft materials, previous transplantation, and use of a ventricular assist device. ${ }^{9}$ Thresholds of cPRA acceptable for transplantation are institution-specific. Patients with cPRA above a certain threshold may be desensitized to reduce the amount of antibodies. ${ }^{9}$

\section{SURGICAL TECHNIQUES}

Orthotopic vs Heterotopic Cardiac Transplantation

In orthotopic cardiac transplantation, the recipient's heart is removed and replaced with a donor heart. This technique is the most widely used in the modern era. ${ }^{10}$ In heterotopic cardiac transplantation, the donor's heart is transplanted and the recipient's own heart is left in place. Although the technique is rarely used these days, the principal advantage of heterotopic transplantation was to allow the patient's native heart to assist the donor heart in cases of severe rejection or donor heart right ventricular failure. ${ }^{10}$

\section{Biatrial vs Bicaval Anastomoses}

In the 1960s, Shumway and colleagues described the biatrial technique in which the donor and recipient hearts were dissected at the midatrial level. ${ }^{11}$ This technique was revolutionary for cardiac transplantation because it allowed surgeons to overcome the technical challenge of pulmonary venous and caval anastomoses to the atrium. This technique, however, resulted in a loss of atrial contractility, atrioventricular discordance, and regurgitation. ${ }^{12}$

In 1990, Yacoub et al described the bicaval technique in which the left atrial cuff on the donor heart was attached to the pulmonary venous cuff of the recipient heart. ${ }^{13}$ This technique allowed for preserved atrial anatomy, contractility, sinus node competence, and valvular function.

Figure 2 illustrates the biatrial and bicaval techniques. ${ }^{14}$

Studies comparing both techniques have shown that the bicaval technique reduced rates of atrial arrhythmias, atrioventricular blocks requiring pacing, tricuspid regurgitation, average length of hospital stay posttransplantation, and average mean arterial pressure at 1, 4, and 12 weeks postoperatively. ${ }^{12,15}$ Although the bicaval technique takes longer to complete than the biatrial technique and prolongs ischemic time, a 2010 review of 20,999 transplants noted a significant advantage in 30 -day mortality in the bicaval group. ${ }^{15}$ 
Table 1. Indications for Heart Transplant Waitlisting ${ }^{6-7}$

\begin{tabular}{|c|c|}
\hline Indications & Contraindications \\
\hline $\begin{array}{l}\text { Cardiogenic shock requiring intravenous inotropes } \\
\text { (dobutamine, milrinone, etc) } \\
\text { Refractory cardiogenic shock requiring IABP or LVAD } \\
\text { Peak } \mathrm{VO}_{2}<10 \mathrm{~mL} / \mathrm{kg} / \mathrm{min} \\
\mathrm{NYHA} \text { III or IV despite maximal medical or resynchronization } \\
\text { therapy } \\
\text { Recurrent life-threatening left ventricular arrhythmias despite } \\
\text { use of ICD, antiarrhythmic therapy, or catheter-based ablation } \\
\text { End-stage congenital heart failure without evidence of } \\
\text { pulmonary hypertension } \\
\text { Refractory angina without potential medical or surgical } \\
\text { therapeutic options }\end{array}$ & $\begin{array}{l}\text { Absolute contraindications } \\
\text { Irreversible liver disease } \\
\text { Irreversible pulmonary parenchymal disease (or FEV } 1<1 \mathrm{~L} / \mathrm{min} \text { ) } \\
\text { Irreversible pulmonary artery hypertension (PASP }>60 \mathrm{mmHg} \text {, } \\
\text { PVR }>5 \text { Wood units despite use of vasodilators) } \\
\text { Clinically severe symptomatic cerebrovascular disease } \\
\text { History of solid organ or hematologic malignancy } \\
\text { Severe irreversible multisystem disease process } \\
\text { Relative contraindications } \\
\text { Age }>70 \text { years } \\
\text { Severe obesity (BMI }>35 \text { kg/m²) or cachexia } \\
\text { Diabetes with end organ damage other than nonproliferative } \\
\text { retinopathy or persistent poor glycemic control (HbA1c } \\
>7.5 \% \text { or } 58 \text { mmol/mol) despite best effort } \\
\text { Irreversible renal dysfunction (GFR }<30 \text { mL/min/1.73 m²) } \\
\text { Severe peripheral vascular disease } \\
\text { Severe cerebrovascular disease } \\
\text { Severe osteoporosis } \\
\text { Acute pulmonary embolism (within } 6 \text { to } 8 \text { weeks) } \\
\text { Active infection (excluding LVAD-related infections) } \\
\text { Psychological instability } \\
\text { Substance abuse within } 6 \text { months (alcohol, cocaine, opioids, } \\
\text { tobacco products) } \\
\text { Lack of social support or sufficient resources to permit ongoing } \\
\text { access to immunosuppressive medication and frequent } \\
\text { medical follow-up } \\
\text { Inability to comply with drug therapy on multiple occasions }\end{array}$ \\
\hline
\end{tabular}

BMI, body mass index; $\mathrm{FEV}_{1}$, forced expiratory volume in the first second of expiration; GFR, glomerular filtration rate; HbA1C, hemoglobin A1c; IABP, intraaortic balloon pump; ICD, implantable cardioverter-defibrillator; LVAD, left ventricular assist device; NYHA, New York Heart Association; PASP, pulmonary artery systolic pressure; PVR, pulmonary vascular resistance; $\mathrm{VO}_{2}$, oxygen consumption.

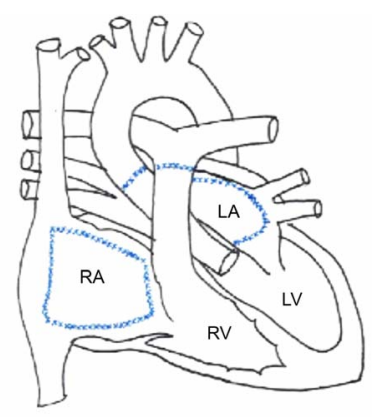

Biatrial technique: heart is dissected at the midatrial level (RA and LA). Great arteries are dissected above the semilunar valves.

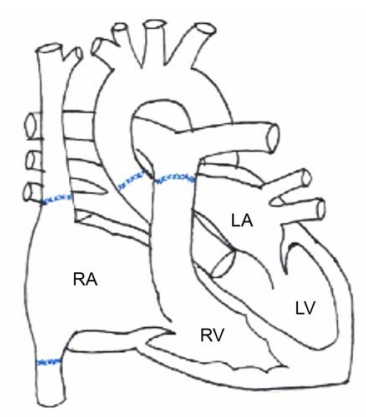

Bicaval technique: heart is dissected at the level of SVC and IVC as they enter the RA. preserving the sinus node. Great arteries are dissected above the semilunar valves.

Figure 2. Surgical techniques of heart transplantation. ${ }^{14} \mathrm{IVC}$, inferior vena cava; LA, left atrium; LV, left ventricle; RA, right atrium; RV, right ventricle; SVC, superior vena cava.

\section{CHRONIC IMMUNOSUPPRESSION}

Posttransplant, immunosuppression typically consists of a triple-therapy regimen that includes calcineurin inhibitors (CNIs), purine synthesis inhibitors, and corticosteroids. ${ }^{1}$ CNIs include cyclosporine and tacrolimus. Purine synthesis inhibitors include mycophenolate mofetil (MMF) and azathioprine. MMF has been shown to be superior to azathioprine in preventing rejection and mortality. ${ }^{16}$ Corticosteroids are

usually prescribed in high doses initially with a gradual taper starting at 6 months posttransplantation. ${ }^{16}$

Proliferation signal inhibitors (sirolimus or everolimus) are usually added to the standard regimen (or in lieu of tacrolimus) in the setting of cardiac allograft vasculopathy or worsening renal function. ${ }^{1}$

Table 3 describes the most commonly used maintenance regimens. ${ }^{17}$

\section{EARLY COMPLICATIONS FOLLOWING CARDIAC TRANSPLANTATION Primary Graft Dysfunction}

Primary graft dysfunction-a syndrome in which the transplanted heart fails to meet the circulatory requirements of the recipient early in the posttransplant period-occurs in $7.4 \%$ of heart transplants and has a 30 -day mortality of $30 \%$, making it the most common cause of mortality during the first month after transplant. ${ }^{18}$ Risk factors for graft dysfunction include older donor age, female donor, non-head trauma as cause of death, coronary artery disease in the donor, older recipient age, prolonged ischemic time ( $>240$ minutes), and donor-to-recipient size mismatch. ${ }^{19}$

When primary graft dysfunction is clinically suspected, immediate bedside echocardiography should be performed to assess for left ventricular or right ventricular failure. Treatment ranges from pharmacologic management using inotropic therapy to MCS in severe cases. ${ }^{17}$ 
Table 2. United Network for Organ Sharing Heart Allocation System as of October $2018^{8}$

\begin{tabular}{|c|c|}
\hline Status & Criteria \\
\hline \multirow[t]{3}{*}{ Status 1} & Venoarterial extracorporeal membrane oxygenation \\
\hline & Nondischargeable, surgically implanted, nonendovascular biventricular support device \\
\hline & Mechanical circulatory support with life-threatening ventricular arrhythmias \\
\hline \multirow[t]{7}{*}{ Status 2} & Nondischargeable, surgically implanted, nonendovascular left ventricular assist device \\
\hline & Intraaortic balloon pump \\
\hline & Ventricular tachycardia or ventricular fibrillation \\
\hline & Mechanical circulatory support with device malfunction/mechanical failure \\
\hline & Total artificial heart, biventricular assist device, right ventricular assist device, or \\
\hline & ventricular assist device for single ventricular patients \\
\hline & Percutaneous endovascular mechanical circulatory support device \\
\hline \multirow[t]{10}{*}{ Status 3} & Dischargeable left ventricular assist device for up to 30 days \\
\hline & Multiple inotropes or single high-dose inotropes with continuous hemodynamic monitoring \\
\hline & $\begin{array}{l}\text { Venoarterial extracorporeal membrane oxygenation after } 7 \text { days; percutaneous endovascular circulatory device or } \\
\text { intraaortic balloon pump after } 14 \text { days }\end{array}$ \\
\hline & Nondischargeable, surgically implanted, nonendovascular left ventricular assist device after 14 days \\
\hline & Mechanical circulatory support with device infection \\
\hline & Mechanical circulatory support with hemolysis \\
\hline & Mechanical circulatory support with pump thrombosis \\
\hline & Mechanical circulatory support with right heart failure \\
\hline & Mechanical circulatory support with mucosal bleeding \\
\hline & Mechanical circulatory support with aortic insufficiency \\
\hline \multirow[t]{8}{*}{ Status 4} & Stable left ventricular assist device candidates not using 30-day discretionary period \\
\hline & Inotropes with hemodynamic monitoring \\
\hline & Retransplant \\
\hline & Diagnosis of congenital heart disease \\
\hline & Diagnosis of ischemic heart disease with intractable angina \\
\hline & Diagnosis of hypertrophic cardiomyopathy \\
\hline & Diagnosis of restrictive cardiomyopathy \\
\hline & Diagnosis of amyloidosis \\
\hline Status $5^{\mathrm{a}}$ & Combined organ transplants \\
\hline Status 6 & All remaining active candidates \\
\hline Status 7 & Inactive/not transplantable \\
\hline
\end{tabular}

a Status 5 candidates may ascend to higher acuity status if indicated based on cardiac status.

\section{Acute Right Ventricular Failure}

Acute refractory right ventricular failure occurs in $2 \%$ to $3 \%$ of patients after cardiac transplantation, although mortality is $>50 \% .{ }^{19,20}$ The etiology of right ventricular failure may be multifactorial, including prolonged ischemiareperfusion time, elevated pulmonary vascular resistance, volume overload, inadequate preload, and donor size mismatch. ${ }^{21}$ Preoperative pulmonary hypertension, specifically pulmonary vascular resistance $>6$ Wood units and mean transpulmonary gradient $>15 \mathrm{mmHg}$ pretransplant, is associated with a higher incidence of right ventricular failure and perioperative mortality. ${ }^{21,22}$ Management of right ventricular failure and pulmonary hypertension usually includes the use of inotropes, nitric oxide, optimization of volume, and cardioversion in cases of dyssynchrony between the sinoatrial node and atrioventricular nodes. ${ }^{17}$ Right ventricular assist devices may be used in cases of severe right ventricular failure. ${ }^{17}$

\section{Conduction Abnormalities}

Owing to denervation of the donor heart, the loss of parasympathetic efferent signals from the vagus nerve to the sinoatrial node, along with the loss of sympathetic efferent signals to the atria and ventricles, leads to an altered response of baroreceptors. ${ }^{23}$ In the setting of hypotension, the absence of activation of carotid and aortic baroreceptors via the sympathetic system results in an inadequate increase in cardiac output that in turn contributes to further hemodynamic instability in the posttransplant period. ${ }^{23}$ 
Table 3. Maintenance Immunosuppression Regimen ${ }^{17}$

\begin{tabular}{|c|c|c|}
\hline Drug & Dosing & Side Effects \\
\hline \multicolumn{3}{|c|}{ Calcineurin inhibitors } \\
\hline \multirow[t]{6}{*}{ Cyclosporine } & $\begin{array}{l}\text { 4-8 } \mathrm{mg} / \mathrm{kg} / \text { day in } 2 \text { divided doses, titrated to } \\
\text { keep target } 12 \text {-hour trough levels }\end{array}$ & $\begin{array}{l}\text { Renal insufficiency } \\
\text { Hypertension and dyslipidemia }\end{array}$ \\
\hline & & Hypokalemia and hypomagnesemia \\
\hline & & Hyperuricemia \\
\hline & & Neurotoxicity (encephalopathy, seizures, tremors, neuropathy) \\
\hline & & Gingival hyperplasia \\
\hline & & Hirsutism \\
\hline \multirow[t]{5}{*}{ Tacrolimus } & $\begin{array}{l}0.05-0.1 \mathrm{mg} / \mathrm{kg} / \text { day in } 2 \text { divided doses, } \\
\text { titrated to keep target } 12 \text {-hour trough } \\
\text { levels }\end{array}$ & $\begin{array}{l}\text { Renal dysfunction } \\
\text { Hypertension } \\
\text { Hyperglycemia and diabetes mellitus }\end{array}$ \\
\hline & & Dyslipidemia \\
\hline & & Hyperkalemia \\
\hline & & Hypomagnesemia \\
\hline & & Neurotoxicity (tremors, headaches) \\
\hline \multicolumn{3}{|l|}{ Cell cycle agents } \\
\hline \multirow[t]{3}{*}{ Azathioprine } & $\begin{array}{l}1.5-3.0 \mathrm{mg} / \mathrm{kg} / \text { day, titrated to maintain white } \\
\text { blood cell level at approximately } 3 \mathrm{~K}\end{array}$ & $\begin{array}{l}\text { Bone marrow suppression } \\
\text { Hepatitis (rare) }\end{array}$ \\
\hline & & Pancreatitis \\
\hline & & Malignancy \\
\hline $\begin{array}{l}\text { Mycophenolate } \\
\text { mofetil }\end{array}$ & 2,000-3,000 mg/day in 2 divided doses & $\begin{array}{l}\text { Gastrointestinal (nausea, gastritis, diarrhea) } \\
\text { Leukopenia }\end{array}$ \\
\hline \multicolumn{3}{|c|}{ Proliferation signal inhibitors } \\
\hline \multirow[t]{7}{*}{ Sirolimus } & $\begin{array}{l}\text { 1-3 mg/day, titrated to keep therapeutic } \\
\text { 24-hour trough levels }\end{array}$ & $\begin{array}{l}\text { Oral ulcerations } \\
\text { Hypercholesterolemia and hypertriglyceridemia }\end{array}$ \\
\hline & & Poor wound healing \\
\hline & & Lower extremity edema \\
\hline & & Pulmonary toxicities (pneumonitis, alveolar hemorrhage) \\
\hline & & Leukopenia, anemia, and thrombocytopenia \\
\hline & & Pericardial effusion \\
\hline & & Potentiation of calcineurin inhibitor nephrotoxicity \\
\hline \multirow[t]{7}{*}{ Everolimus } & $1.5 \mathrm{mg} /$ day in 2 divided doses & Oral ulcerations \\
\hline & & Hypercholesterolemia and hypertriglyceridemia \\
\hline & & Poor wound healing \\
\hline & & Lower extremity edema \\
\hline & & Pulmonary toxicities (pneumonitis, alveolar hemorrhage) \\
\hline & & Leukopenia, anemia, and thrombocytopenia \\
\hline & & Potentiation of calcineurin inhibitor nephrotoxicity \\
\hline \multicolumn{3}{|l|}{ Corticosteroids } \\
\hline \multirow[t]{7}{*}{ Prednisone } & $\begin{array}{l}1 \mathrm{mg} / \mathrm{kg} / \text { day in } 2 \text { divided doses, tapered to } \\
0.05 \mathrm{mg} / \mathrm{kg} / \text { day by } 6-12 \text { months }\end{array}$ & $\begin{array}{l}\text { Weight gain } \\
\text { Hypertension, hyperlipidemia, hyperglycemia }\end{array}$ \\
\hline & & Osteopenia \\
\hline & & Poor wound healing \\
\hline & & Salt and water retention \\
\hline & & Proximal myopathy \\
\hline & & Cataracts \\
\hline & & Peptic ulcer disease \\
\hline
\end{tabular}


Right and left bundle branch blocks may also result from surgical trauma to the conduction system or prolonged ischemic time. ${ }^{23}$ Epicardial pacing is commonly used intraoperatively at the time of heart transplantation to maintain cardiac output with heart rates between 100 and $120 \mathrm{bpm}$. Chronotropic agents may be used to further augment heart rate. In cases of persistent bradycardia, permanent pacing can be considered. ${ }^{17}$

\section{Other Common Postoperative Complications}

A retrospective study of 239 patients after heart transplantation identified the most common nonfatal complications to be pericardial effusion (61.5\%), arrhythmias (41.8\%), and mediastinal bleeds (8.4\%). ${ }^{24}$ Pericardial effusion can be diagnosed clinically and confirmed by echocardiogram. An effusion that is hemodynamically stable usually does not need intervention. While vascular trauma may result from surgical incisions, the use of cardiopulmonary bypass intraoperatively may cause a decrease in coagulation factors and platelets and therefore contribute to bleeding risk. ${ }^{24,25}$ In addition, hypothermia and intraoperative use of heparin exacerbate abnormal hemostasis. ${ }^{24,25}$ Conservative management of acute blood loss anemia includes conducting interval checks of blood count and transfusing compatible leukocyte-reduced packed red blood cells. Platelets should be avoided except in cases of excessive bleeding. ${ }^{17}$ Mediastinal bleeds require a cardiothoracic surgery consultation and evaluation for intervention, including repair of tear or muscle flap. ${ }^{17,24,25}$

\section{CARDIAC REJECTION}

Three types of rejection can occur posttransplant: hyperacute rejection, acute cellular rejection, and antibodymediated rejection. Hyperacute rejection occurs intraoperatively immediately after the aortic cross-clamp is removed and the donor heart is exposed to the recipient's red blood cells. Because of cross-matching of blood type and panel reactive antibodies, hyperacute rejection is now uncommon.

Acute cellular rejection is a $\mathrm{T}$ cell reaction that occurs in $20 \%$ to $40 \%$ of patients, most commonly during the first 12 months posttransplant. ${ }^{26}$ Acute cellular rejection is mediated by the recipient's T cells recognizing the donor's human leukocyte antigen (HLA) molecules and is characterized by an inflammatory infiltrate on endomyocardial biopsy (EMB). ${ }^{26}$ Acute cellular rejection is classified based on the severity of lymphocytic infiltrate and myocyte damage (grades 0 to 3); treatment typically includes high-dose corticosteroids. ${ }^{17}$ If the patient has hemodynamic instability or shows no improvement 12 to 24 hours after steroid administration, antithymocyte antibodies should be used. ${ }^{17}$ $A$ repeat EMB is usually performed 1 to 2 weeks after treatment for follow-up. ${ }^{17}$

Antibody-mediated rejection is seen in $10 \%$ to $20 \%$ of patients and has a mortality rate of $8 \% .{ }^{27,28}$ In antibodymediated rejection, donor antigens and recipient antibodies form an antigen-antibody complex, or a membrane attack complex, that results in endothelial and vascular injury. The diagnosis of antibody-mediated rejection is confirmed by the presence of circulating donor-specific antibodies and via EMB with immunopathologic evidence of complement activation (C4d, C3d, CD68). Management of antibodymediated rejection includes intravenous immunoglobu- lin, plasmapheresis, antilymphocyte antibodies, and highdose corticosteroids. ${ }^{17}$ The maintenance immunosuppression regimen is typically optimized in the setting of antibodymediated rejection, and rituximab may be added as a second-line agent to reduce the risk of recurrent rejection. ${ }^{17}$

While EMB is the gold standard screening test for rejection, it is an invasive procedure that has associated risks. ${ }^{17}$ AlloMap (CareDx) is now an approved noninvasive screening test for acute cellular rejection in low-risk patients. ${ }^{29}$ Using polymerase chain reaction, this test measures the expression of 20 genes and generates a score ranging from 0 to 40 . Scores $<34$ have been associated with a low likelihood of moderate to severe cardiac allograft rejection. ${ }^{29}$ This test is currently widely used and has helped transplant centers reduce the number of EMBs needed after cardiac transplantation. ${ }^{29,30}$

\section{LATE COMPLICATIONS FOLLOWING CARDIAC TRANSPLANTATION}

Long-term outcomes for cardiac transplant recipients remain suboptimal, with a median cardiac allograft survival of 11 years. ${ }^{31}$ Long-term posttransplant complications include chronic allograft vasculopathy, increased risk of malignancies, opportunistic infections, and renal insufficiency. ${ }^{31}$

\section{Chronic Allograft Vasculopathy}

Chronic allograft vasculopathy is accelerated atherosclerosis of blood vessels after cardiac transplantation and has an estimated incidence of $8 \%$ in the first year, $20 \%$ at 3 years, $30 \%$ at 5 years, and $>50 \%$ at 10 years. ${ }^{31}$ Risk factors include older donor and recipient age, history of diabetes mellitus, hypertension, mismatch of body size, and mismatch of HLA. ${ }^{32}$ Because the donor heart is denervated during transplantation, cardiac transplant patients do not have typical anginal pain but rather atypical clinical presentations such as HF, arrhythmias, or sudden cardiac death. ${ }^{32}$ The International Society for Heart and Lung Transplantation (ISHLT) recommends the use of intravascular ultrasound in conjunction with coronary angiogram 4 to 6 weeks after transplant followed by annual or biannual intervals to detect chronic allograft vasculopathy. ${ }^{31}$ Noninvasive testing with dobutamine stress echocardiogram may be done initially at 6 months posttransplant for baseline quantification of cardiac chamber sizes, pulmonary artery pressure, and right and left ventricular function and can be repeated to lengthen the interval time between angiographic screenings. Cardiac magnetic resonance and positron emission tomography tests have diagnostic accuracy for early chronic allograft vasculopathy detection. ${ }^{32,33}$ Gene profiling has also emerged as a promising noninvasive technique to detect chronic allograft vasculopathy. ${ }^{32,33}$

If chronic allograft vasculopathy is localized, stenting with percutaneous coronary intervention can be attempted. If diffused, treatment consists of modifying immunosuppression, considering the use of everolimus (a drug that has been shown to reduce the incidence of chronic allograft vasculopathy), ${ }^{34}$ and increasing the statin dose. Retransplantation may be considered for patients who develop chronic allograft vasculopathy refractory to medical and interventional therapy and have symptoms of HF or ischemia. ${ }^{17}$ 


\section{Infection}

Infection is a common complication in the acute and chronic setting posttransplant, accounting for $30 \%$ mortality during the first year followed by a decline to $10 \%$ to $13 \%$ per year. ${ }^{1}$ The predominant infections during the first month and during the first 6 months are bacterial septicemia and pulmonary infections, respectively. ${ }^{35} \mathrm{~A}$ viral infection, especially cytomegalovirus (CMV), may predispose a patient to a bacterial infection. ${ }^{35}$ Seventy-five percent of pneumonia cases occur during the first 3 months posttransplant, with most causal agents being opportunistic (60\%) and nosocomial (25\%), namely CMV, Aspergillus species, and Pneumocystis jirovecii. ${ }^{35}$ Typically, preventive vaccinations against pneumococcal pneumonia and influenza are administered prior to transplant. Posttransplant, prophylactic therapy for Pneumocystis jirovecii pneumonia, herpes simplex virus, toxoplasmosis, and oral candidiasis should be started. Recipients of CMV-positive hearts who are inherently CMV-negative must also receive prophylactic antiviral therapy. ${ }^{17}$

\section{Malignancy}

Malignancies are a risk post cardiac transplantation, specifically skin cancer (18\%) and lymphoma (1.9\%). ${ }^{1}$ Patients should visit the dermatologist yearly for evaluation of any suspicious lesion and receive age-appropriate cancer screening from their primary care physician. ${ }^{17}$ While reduction of steroid dose in the setting of malignancy is controversial, use of proliferation signal inhibitors, such as sirolimus, may be considered. ${ }^{36}$

\section{Chronic Kidney Disease}

Chronic kidney disease (CKD) is common in up to $50 \%$ of patients 5 years after heart transplantation, with $6 \%$ requiring dialysis by 10 years posttransplant. ${ }^{36}$ Risk factors include older age, female sex, lower pretransplant glomerular filtration rate (GFR), and pretransplant inotrope or MCS use. ${ }^{37}$ CNIs, a mainstay of immunosuppression after cardiac transplantation, contribute to a yearly risk of progressive CKD and overall mortality 5 years posttransplant. ${ }^{36}$ To prevent progression, renal function must be monitored regularly, renal toxins should be minimized, and the $\mathrm{CNI}$ dose should be reduced. Referral to a nephrologist should be considered if GFR falls below $30 \mathrm{~mL} / \mathrm{min} / 1.73 \mathrm{~m}^{2}$ or in cases of significant proteinuria (>500 mg/d). ${ }^{17}$ Strict glucose and blood pressure control helps slow progression of CKD. Hemoglobin should be measured once yearly in all cardiac transplant recipients with CKD with the goal of maintaining levels of 11 to 13 g/dL. ${ }^{17}$

Because CNls have a significant effect on progressive renal disease, a randomized controlled trial evaluated whether substituting everolimus for a CNI 7 to 11 weeks after cardiac transplantation affected renal function. ${ }^{38}$ The study noted a protective effect on the GFR measured 12 and 36 months posttransplant in the group that was switched from a $\mathrm{CNI}$ to everolimus while maintaining other immunosuppression with mycophenolic acid and corticosteroids. ${ }^{38}$ However, this group also had higher rates of biopsy-proven acute rejection episodes and serious adverse events at 36 months posttransplant. ${ }^{38}$ Therefore, early withdrawal of CNIs may only be an option for carefully selected cardiac transplan- tation recipients with severe renal function while acknowledging the potential for rejection.

\section{Other Steroid-Related Complications}

Corticosteroids are a mainstay of immunosuppression after cardiac transplantation and are associated with a number of steroid-related comorbidities, including bone disease, diabetes, hypertension, and hyperlipidemia. Steroidinduced bone disease is prevalent in $25 \%$ to $50 \%$ of patients post cardiac transplantation and is associated with a $10 \%$ to $36 \%$ increased incidence of fractures. ${ }^{39}$ All cardiac transplant recipients should be screened for preexisting bone disease prior to transplant and prescribed calcium and vitamin D supplements to maintain vitamin D levels $>30 \mathrm{ng} / \mathrm{mL} .{ }^{17}$ ISHLT recommends taking bisphosphonates to minimize bone resorption. ${ }^{17}$ While steroid-induced diabetes may be prevalent in $23 \%$ of patients during the first year after cardiac transplantation, early withdrawal of steroids after transplantation may result in a decreased prevalence of diabetes therafter. ${ }^{40}$ Steroid withdrawal can be achieved in $50 \%$ to $80 \%$ of patients without an increase in rejection-related mortality. ${ }^{40}$ In addition, patients weaned off steroids and those who are maintained on low-dose maintenance corticosteroid therapy may have a decreased prevalence of comorbidities, as well as decreased incidence and progression of cardiac allograft vasculopathy. ${ }^{40,41}$

\section{CURRENT CHALLENGES AND FUTURE DIRECTIONS}

Cardiac transplantation has progressed greatly since the first successful operation in 1967. ${ }^{2}$ However, many challenges still face physicians and heart transplant recipients.

The most critical issue is the growing number of patients on the waitlist and the relatively stagnant donor pool. ${ }^{42}$ The hope is that the new UNOS heart allocation system will allow previously disadvantaged patients such as patients with congenital heart disease, infiltrative cardiomyopathy, and refractory arrhythmias to obtain transplants in a timely fashion. ${ }^{43,44}$

In addition to optimizing the heart allocation system, further advances are needed in monitoring and preventing rejection of transplanted organs. ${ }^{45}$ The current gold standard for monitoring rejection in recipients is right ventricle EMB, an invasive procedure that has risks. However, research from 2010 suggests that gene expression profiling is noninferior to EMB in assessing the composite primary outcome of rejection. ${ }^{46}$ While the results of this study suggest a lessinvasive alternative to routine biopsy for monitoring rejection in patients 6 months after transplant, further comparative studies are necessary before the relative safety of this method as an alternative to EMB can be demonstrated. ${ }^{46}$

More research is necessary to fill high-priority knowledge gaps in cardiac transplantation, including waitlist mortality on the new allocation system, individualizing immunosuppression regimens, and a more complete understanding of antibody-mediated rejection. ${ }^{47}$

\section{CONCLUSION}

Cardiac transplantation remains the only panacea for end-stage HF. The tremendous progress in surgical techniques and immunosuppression regimens has led to better 
outcomes. Nevertheless, the limited number of heart donors continues to make this therapy a road less traveled.

\section{ACKNOWLEDGMENTS}

The authors have no financial or proprietary interest in the subject matter of this article.

\section{REFERENCES}

1. Lund LH, Edwards LB, Dipchand Al, et al; International Society for Heart and Lung Transplantation. The Registry of the International Society for Heart and Lung Transplantation: thirty-third adult heart transplantion report-2016; focus theme: primary diagnostic indications for transplant. J Heart Lung Transplant. 2016 Oct;35(10):1158-1169. doi: 10.1016/j.healun.2016.08.017.

2. DiBardino DJ. The history and development of cardiac transplantation. Tex Heart Inst J. 1999;26(3):198-205.

3. Colvin M, Smith JM, Hadley N, et al. OPTN/SRTR 2016 annual data report: heart. Am J Transplant. 2018 Jan;18 Suppl 1:291-362. doi: 10.1111/ajt.14561.

4. Lund LH, Edwards LB, Kucheryavaya AY, et al; International Society of Heart and Lung Transplantation. The Registry of the International Society for Heart and Lung Transplantation: thirty-first official adult heart transplant report-2014; focus theme: retransplantation. J Heart Lung Transplant. 2014 Oct;33(10):996-1008. doi: 10.1016/j.healun.2014.08.003.

5. Alraies MC, Eckman P. Adult heart transplant: indications and outcomes. J Thorac Dis. 2014 Aug;6(8):1120-1128. doi: 10.3978/j.issn.2072-1439.2014.06.44.

6. Jessup M, Abraham WT, Casey DE, et al. 2009 focused update: ACCF/AHA guidelines for the diagnosis and management of heart failure in adults: a report of the American College of Cardiology Foundation/American Heart Association Task Force on Practice Guidelines: developed in collaboration with the International Society for Heart and Lung Transplantation. Circulation. 2009 Apr 14;119(14):1977-2016.

7. Mancini D, Lietz K. Selection of cardiac transplantation candidates in 2010. Circulation. $2010 \mathrm{Jul} 13 ; 122(2): 173-183$. doi: 10.1161/CIRCULATIONAHA.109.858076.

8. United Network for Organ Sharing. unos.org. Accessed November 14, 2019.

9. Nwakanma LU, Williams JA, Weiss ES, Russell SD, Baumgartner WA, Conte JV. Influence of pretransplant panel-reactive antibody on outcomes in 8,160 heart transplant recipients in recent era. Ann Thorac Surg. 2007 Nov;84(5):1556-1562; discussion 1562-1563. doi: 10.1016/j.athoracsur.2007.05.095.

10. Newcomb AE, Esmore DS, Rosenfeldt FL, Richardson M, Marasco SF. Heterotopic heart transplantation: an expanding role in the twenty-first century? Ann Thorac Surg. 2004 Oct;78(4):1345-1350; discussion 1350-1351. doi: 10.1016/j.athoracsur.2004.03.071.

11. Shumway NE, Lower RR, Stofer RC. Transplantation of the heart. Adv Surg. 1966;2:265-284.

12. el Gamel A, Yonan NA, Grant S, et al. Orthotopic cardiac transplantation: a comparison of standard and bicaval Wythenshawe techniques. J Thorac Cardiovasc Surg. 1995 Apr;109(4): 721-729; discussion 729-730. doi: 10.1016/S0022-5223(95)70354-3.

13. Yacoub M, Mankad $P$, Ledingham S. Donor procurement and surgical techniques for cardiac transplantation. Semin Thorac Cardiovasc Surg. 1990 Apr;2(2):153-161.

14. Morgan JA, Edwards NM. Orthotopic cardiac transplantation: comparison of outcome using biatrial, bicaval, and total techniques. J Card Surg. 2005 Jan-Feb;20(1):102-106.
15. Davies RR, Russo MJ, Morgan JA, Sorabella RA, Naka Y, Chen $J M$. Standard versus bicaval techniques for orthotopic heart transplantation: an analysis of the United Network for Organ Sharing database. J Thorac Cardiovasc Surg. 2010 Sep;140(3):700-708, 708.e1-e2. doi: 10.1016/j.jtcvs.2010.04.029.

16. Kobashigawa J, Miller L, Renlund D, et al. A randomized active-controlled trial of mycophenolate mofetil in heart transplant recipients. Mycophenolate Mofetil Investigators. Transplantation. 1998 Aug 27; 66(4):507-515. doi: 10.1097/00007890-199808270-00016.

17. Costanzo MR, Dipchand A, Starling R, et al; International Society of Heart and Lung Transplantation Guidelines. The International Society of Heart and Lung Transplantation Guidelines for the care of heart transplant recipients. J Heart Lung Transplant. 2010 Aug;29(8):914-956. doi: 10.1016/j.healun.2010.05.034.

18. Kobashigawa J, Zuckermann A, Macdonald P, et al; Consensus Conference participants. Report from a consensus conference on primary graft dysfunction after cardiac transplantation. J Heart Lung Transplant. 2014 Apr;33(4):327-340. doi: 10.1016/j.healun.2014.02.027.

19. McCartney SL, Patel C, Del Rio JM. Long-term outcomes and management of the heart transplant recipient. Best Pract Res Clin Anaesthesiol. 2017 Jun;31(2):237-248. doi: 10.1016/j.bpa.2017.06.003.

20. Kaul TK, Fields BL. Postoperative acute refractory right ventricular failure: incidence, pathogenesis, management and prognosis. Cardiovasc Surg. 2000 Jan;8(1):1-9. doi: 10.1016/s0967-2109(99)00089-7.

21. Haddad F, Couture P, Tousignant C, Denault AY. The right ventricle in cardiac surgery, a perioperative perspective: II. Pathophysiology, clinical importance, and management. Anesth Analg. 2009 Feb;108(2):422-433. doi: 10.1213/ane.0b013e31818d8b92.

22. Leeman $M$, Van Cutsem $M$, Vachiéry JL, Antoine M, Leclerc JL. Determinants of right ventricular failure after heart transplantation. Acta Cardiol. 1996;51(5):441449.

23. Awad M, Czer LS, Hou M, et al. Early denervation and later reinnervation of the heart following cardiac transplantation: a review. J Am Heart Assoc. 2016 Nov 1;5(11). pii: e004070. doi: 10.1161/JAHA.116.004070.

24. Birati EY, Rame JE. Post-heart transplant complications. Crit Care Clin. 2014 Jul;30(3):629-637. doi: 10.1016/j.ccc.2014.03.005.

25. Kim HJ, Jung SH, Kim JJ, et al. Early postoperative complications after heart transplantation in adult recipients: Asan Medical Center experience. Korean J Thorac Cardiovasc Surg. 2013 Dec;46(6):426-432. doi: 10.5090/kjtcs.2013.46.6.426.

26. Chang DH, Kittleson MM, Kobashigawa JA. Immunosuppression following heart transplantation: prospects and challenges. Immunotherapy. 2014;6(2):181-194. doi: 10.2217/imt.13.163.

27. Kobashigawa JA, Patel JK, Kittleson MM, et al. The long-term outcome of treated sensitized patients who undergo heart transplantation. Clin Transplant. 2011 Jan-Feb; 25(1):E61-67. doi: 10.1111/j.1399-0012.2010.01334.x.

28. Lund LH, Edwards LB, Kucheryavaya AY, et al. The Registry of the International Society for Heart and Lung Transplantation: thirty-second official adult lung and heart-lung transplantation report-2015; focus theme: early graft failure. J Heart Lung Transplant. 2015 Oct;34(10):1244-1254. doi: 10.1016/j.healun.2015.08.003.

29. Deng MC, Eisen HJ, Mehra MR, et al. Noninvasive discrimination of rejection in cardiac allograft recipients using 
gene expression profiling. Am J Transplant. 2006 Jan;6(1):150-160. doi: 10.1111/j.1600-6143.2005.01175.x.

30. Hullin R. Heart transplantation: current practice and outlook to the future. Swiss Med Wkly. 2014 Aug 7;144:w13977. doi: 10.4414/smw.2014.13977.

31. Stehlik J, Edwards LB, Kucheryavaya AY, et al. The Registry of the International Society for Heart and Lung Transplantation: twenty-seventh official adult heart transplant report-2010. J Heart Lung Transplant. 2010 Oct;29(10):1089-1193. doi: 10.1016/j.healun.2010.08.007.

32. Ramzy D, Rao V, Brahm J, Miriuka S, Delgado D, Ross HJ. Cardiac allograft vasculopathy: a review. Can J Surg. 2005 Aug;48(4):319-327.

33. Schmauss $D$, Weis M. Cardiac allograft vasculopathy: recent developments. Circulation. 2008 Apr 22;117(16):2131-2141. doi: 10.1161/CIRCULATIONAHA.107.711911.

34. Andreassen AK, Andersson B, Gustafsson F, et al; SCHEDULE investigators. Everolimus initiation with early calcineurin inhibitor withdrawal in De Novo heart transplant recipients: three-year results from the randomized SCHEDULE study. Am J Transplant. 2016 Apr;16(4):1238-1247. doi: 10.1111/ajt.13588.

35. Cisneros JM, Muñoz P, Torre-Cisneros J, et al. Pneumonia after heart transplantation: a multi-institutional study. Spanish Transplantation Infection Study Group. Clin Infect Dis. 1998 Aug;27(2):324-331. doi: 10.1086/514649.

36. Alba Ac, Bain E, Ng N, et al. Complications after heart transplantation: hope for the best, but prepare for the worst. Int J Transplant Res Med. 2016;2(2):1-11. doi: $10.23937 / 2572-4045.1510022$.

37. Lachance $K$, White $M$, de Denus S. Risk factors for chronic renal insufficiency following cardiac transplantation. Ann Transplant. 2015 Sep 29;20:576-587. doi: 10.12659/AOT.893788.

38. Andreassen AK, Andersson B, Gustafsson F, et al; SCHEDULE Investigators. Everolimus initiation and early calcineurin inhibitor withdrawal in heart transplant recipients: a randomized trial. Am J Transplant. 2014 Aug;14(8):1828-1838. doi: $10.1111 /$ ajt.12809.
39. Cohen A, Sambrook P, Shane E. Management of bone loss after organ transplantation. J Bone Miner Res. 2004 Dec;19(12):1919-1932. doi: 10.1359/JBMR.040912.

40. Baraldo M, Gregoraci G, Livi U. Steroid-free and steroid withdrawal protocols in heart transplantation: the review of literature. Transpl Int. 2014 Jun;27(6):515-529. doi: $10.1111 /$ tri.12309.

41. Caforio AL, Tona F, Fortina AB, et al. Immune and nonimmune predictors of cardiac allograft vasculopathy onset and severity: multivariate risk factor analysis and role of immunosuppression. Am J Transplant. 2004 Jun;4(6):962-970. doi: $10.1111 /$ j.1600-6143.2004.00434.x.

42. Transplant trends. United Network for Organ Sharing. unos.org/data/transplant-trends/\#waitlists_by_organ. Accessed June 22, 2018.

43. Meyer DM, Rogers JG, Edwards LB, et al. The future direction of the adult heart allocation system in the United States. Am J Transplant. 2015 Jan;15(1):44-54. doi: 10.1111/ajt.13030.

44. Adult heart allocation criteria for medical urgency status. Organ Procurement and Transplant Network, United Network for Organ Sharing. optn.transplant.hrsa.gov/media/2414/adult_heart infographic.pdf. Accessed July 28, 2019.

45. Becnel MF, Ventura HO, Krim SR. Changing our approach to stage D heart failure. Prog Cardiovasc Dis. 2017 Sep-Oct;60(2):205-214. doi: 10.1016/j.pcad.2017.08.003.

46. Pham MX, Teuteberg JJ, Kfoury AG, et al; IMAGE Study Group. Gen e-expression profiling for rejection surveillance after cardiac transplantation. N Engl J Med. 2010 May 20; 362(20): 1890-1900. doi: 10.1056/NEJMoa0912965.

47. Shah MR, Starling RC, Schwartz Longacre L, Mehra MR; Working Group Participants. Heart transplantation research in the next decade-a goal to achieving evidence-based outcomes: National Heart, Lung, and Blood Institute Working Group. J Am Coll Cardiol. 2012 Apr 3;59(14):1263-1269. doi: 10.1016/j.jacc.2011.11.050.

This article meets the Accreditation Council for Graduate Medical Education and the American Board of Medical Specialties Maintenance of Certification competencies for Patient Care and Medical Knowledge.

C2019 by the author(s); licensee Ochsner Journal, Ochsner Clinic Foundation, New Orleans, LA. This article is an open (c) (i) access article distributed under the terms and conditions of the Creative Commons Attribution (CC BY) license (creativecommons.org/licenses/by/4.0/legalcode) that permits unrestricted use, distribution, and reproduction in any medium, provided the original author(s) and source are credited. 